\title{
Erratum to: Evaluation of the retinal changes in patients with chronic migraine
}

\author{
Serkan Kirbas • Ahmet Tufekci • Kemal Turkyilmaz • \\ Aynur Kirbas · Veysi Oner · Mustafa Durmus
}

Published online: 22 March 2013

(C) Belgian Neurological Society 2013

\section{Erratum to: Acta Neurol Belg}

DOI 10.1007/s13760-012-0150-x

In the published original article, Abstract section, the numbers of the patient group and control group are not given correctly.

The correct numbers are:

24 females, 16 males in the patient group (not 18 females,

12 males).

22 females, 18 males in the control group (not 16 females, 14 males).

The online version of the original article can be found under doi:10.1007/s13760-012-0150-x.

S. Kirbas $(\bowtie) \cdot$ A. Tufekci

Department of Neurology, Faculty of Medicine,

Recep Tayyip Erdogan University, 53100 Rize, Turkey

e-mail: drskirbas@gmail.com

K. Turkyilmaz · V. Oner · M. Durmus

Department of Ophthalmology, Faculty of Medicine,

Recep Tayyip Erdogan University, Rize, Turkey

\section{A. Kirbas}

Department of Biochemistry, Faculty of Medicine,

Recep Tayyip Erdogan University, Rize, Turkey 